\title{
P04.29. Tai chi and health related quality of life: a systematic review and meta-analysis of randomized controlled trials
}

\author{
S Abariga ${ }^{*}$, C Wang \\ From International Research Congress on Integrative Medicine and Health 2012 \\ Portland, Oregon, USA. 15-18 May 2012
}

\section{Purpose}

Tai Chi, a Chinese mind-body exercise, has a complex multicomponent therapy that integrates physical, psychosocial, emotional and behavioral elements to promote health in a variety chronic condition. Health Related Quality of Life (HRQL) is a multidimensional, subjective patient centered outcome that encompasses those conditions that affects a person's overall well-being. A comprehensive review of the literature of Tai Chi and quality of life is an important step for understanding the mind-body beneficial effects. We conducted a systematic review and meta-analysis of randomized controlled trials evaluating the effect Tai Chi on HRQL on a variety of populations.

\section{Methods}

We performed a comprehensive search of 11 data databases through October 2011 with no language restriction. We included randomized controlled trials evaluating Tai Chi in HRQL for both healthy and patients with chronic conditions with a sample size of least 10 subjects; at least two weeks of follow-up and assessed HRQL as an outcome. Study quality was assessed with the Jadad instrument. The differences between treatment groups were reported as mean change (95\% CI, p-value). We also conducted a meta-analysis on studies using the SF-36 quality of life instruments.

\section{Results}

We identified 61 potentially relevant studies and 31 RCTs with a total of 2662 subjects met our eligibility criteria. Of these, six RCTs used SF-36 and 25 used other HRQL measures. Twenty-six of them reported an improvement in HRQL with Tai Chi practice compared with control. The

Tufts Medical Center, Division of Rheumatology, Boston, USA meta-analysis results showed that five RCTs, average quality of four, enrolling 231 patients with 12 to 15 weeks of Tai Chi therapy, had benefit effects. The pooled effect size for the physical component score was 6.08 (95\% CI: 3.7 to $8.45)$ and for the mental component score was 4.12 (95\% CI: 1.32 to 6.93$)$.

\section{Conclusion}

The current body of evidence suggests that Tai Chi may improve HRQL across various disease populations.

Published: 12 June 2012

doi:10.1186/1472-6882-12-S1-P299

Cite this article as: Abariga and Wang: P04.29. Tai chi and health related quality of life: a systematic review and meta-analysis of randomized controlled trials. BMC Complementary and Alternative Medicine 201212 (Suppl 1):P299.

Submit your next manuscript to BioMed Central and take full advantage of:

- Convenient online submission

- Thorough peer review

- No space constraints or color figure charges

- Immediate publication on acceptance

- Inclusion in PubMed, CAS, Scopus and Google Scholar

- Research which is freely available for redistribution 